\title{
PENGGUNAAN EKSTENTION WAKTU DALAM ROLE ONLINE SYSTEM TICKETING RAHARJA (ROOSTER) SEBAGAI PENUNJANG PELAYANAN IDUHELP!
}

\author{
Meta Amalya Dewi ${ }^{1}$ \\ Dewi Immaniar ${ }^{2}$ \\ Siti Rahmawati ${ }^{3}$ \\ e-mail :meta@raharja.info; dewi.immaniar@raharja.info; sitirahma@raharja.info
}

Diterima : 03 Juli 2014 / Disetujui: 21 Juli 2014

\begin{abstract}
Rooster (Role Online System Ticketing Raharja) is an information service by using the " online ticket" which is provided as an advanced container to accommodate questions from iDuHelp! Operators. In ROOSTER (Role Online System Ticketing Raharja) , iDuHelp! Operators acting as a customer that making an advance question which will be accepted by each staff based on their category.The submitted question must be in existed scope. But in ROOSTER service there are still some shortcomings that must be covered for research so it will conlclude many solution. Among many problems, the main problem is the lack of service time, so it can be concluded that the solution is to extend the service time when needed. With this system fix in rooster, iduhelp activity in ROOSTER will perform good.
\end{abstract}

Keywords : ROOSTER, iDuHelp!, Service

\section{ABSTRAKSI}

ROOSTER ("Role Online System Ticketing Raharja”) merupakan pelayanan informasi dengan menggunakan "ticket online” yang sistemnya disediakan sebagai wadah lanjutan untuk menampung pertanyaan yang didapat para operator iDuHelp!. Di Rooster|ROOSTER ("Role Online System Ticketing Raharja") operator iDuHelp! bertindak sebagai customer

1. Dosen Jurusan Sistem Informasi, STMIK Raharja

Jl. Jend Sudirman No. 40 Modern Cikokol-Tangerang Telp. 5529692

2. Dosen Jurusan Sistem Informasi, STMIK Raharja

Jl. Jend Sudirman No. 40 Modern Cikokol-Tangerang Telp. 5529692

3. Mahasiswa Jurusan Sistem Informasi, STMIK Raharja

Jl. Jend Sudirman No. 40 Modern Cikokol-Tangerang Telp. 5529692 
yang membuat pertanyaan lanjutan yang nantinya akan diterima oleh Staff berdasarkan bidangnya masing-masing. Pertanyaan yang diajukan pun berdasarkan ruang lingkup yang ada. Namun pada pelayanan ROOSTER pun masih terdapat beberapa kekurangan yang harus diperbaiki untuk menjadi bahan penelitian sehingga dapat disimpulkan berbagai pemecahan masalahnya. Diantara banyaknya masalah yang ada, masalah utama adalah pelayanan yang terabaikan karena kurangnya waktu pada pelayanannya, maka dapat disimpulkan pemecahannya yaitu dengan adanya sistem penambahan waktu dalam pelayanan jika dibutuhkan. Dengan adanya perbaikan sistem di ROOSTER maka kegiatan iDuHelp! di ROOSTER dapat berjalan dengan baik.

Kata kunci : ROOSTER, iDuHelp!, Pelayanan

\section{PENDAHULUAN}

Teknologi yang semakin pesat menjadi kebutuhan yang sangat penting yang diperlukan untuk siapa saja. Berdampak pada semua aspek kehidupan yang berhubungan dengan suatu penilaian dalam setiap pelayanan yang ada. Bagus atau tidaknya suatu Sistem Informasi dapat dilihat dari kepuasan pada pelayanan tersebut. Jika, pelayanan yang diterima melampaui keinginan customer, maka kualitas pelayanan dipersepsikan sebagai kualitas yang baik. Sebaliknya, jika pelayanan yang diterima lebih rendah daripada yang diinginkan, maka kualitas dipersepsikan buruk.

Contohnya pembayaran yang dilakukan masih secara manual, sehingga membutuhkan waktu yang lama. Dengan demikian, baik tidaknya kualitas pelayanan tergantung pada kemampuan perguruan tinggi dalam memenuhi keinginan mahasiswanya secara konsisten.

Proses pelayanan yang ada terlihat masih banyak dilakukan dengan cara yang masih kurang efesien, sehingga banyak waktu yang terbuang hanya untuk mendapatkan informasi. Salah satu contoh yang paling sederhana adalah mahasiswa hanya untuk mendapatkan informasi harus mengeluarkan banyak waktu dan tenaga, karena saat itu masih menggunakan cara berinteraksi secara fisik (manual), seperti ketika salah satu mahasiswa yang ingin bertanya mengenai perihal seputar lupa username email, mahasiswa tersebut harus mencari

pihak yang berkaitan agar mahasiswa tersebut mendapatkan informasi yang dibutuhkannya. Tapi kini dengan memanfaatkan media komputer yang diakses dengan jaringan internet, Perguruan Tinggi Raharja telah mengembangkan sebuah 
sistem pelayanan yaitu sistem pelayanan iDuHelp!. Sistem pelayanan iDuHelp! merupakan sistem pelayanan informasi yang dapat dilakukan secara insite dan offsite. Pelayanan iDuHelp! yang dilakukan secara insite artinya pelayanan online melalui live chat yang dipandu oleh operator iDuHelp!.

Sedangkan pelayanan iDuHelp! secara offsite artinya pelayanan offline yang dilakukan dengan cara mengirimkan isi pesan kemudian terdapat proses tunggu untuk memperoleh informasi. Di dalam pelayanan tersebut terdapat beberapa operator yang siap sedia melayani para mahasiswa untuk mendapatkan sebuah informasi.

Namun permasalahan yang sering terjadi pada sistem pelayanan iDuHelp! adalah ketika pertanyaan yang diajukan tidak dapat dijawab oleh operator iDuHelp!, karena operator iDuHelp! tidak dapat memprediksi pertanyaan-pertanyaan yang dibutuhkan oleh para pribadi Raharja, sehingga operator iDuHelp! harus mencari tambahan informasi dari pihak yang terkait secara langsung agar dapat menjawab pertanyaan dari mahasiswa.

Hal ini menyebabkan operator iDuHelp! membutuhkan waktu yang lama untuk mendapatkan sebuah informasi yang diperlukan. Oleh karena itu, pelayanan sistem iDuHelp! ini sangat membutuhkan sebuah sistem tambahan agar dapat menunjang proses kegiatan pelayanannya. Saat ini telah adanya sistem ROOSTER (Role Online system Ticketing Raharja) yang dapat memaksimalkan kegiatan pelayanan yang ada di iDuHelp!.

Saat ini telah dilakukan berbagai cara untuk meningkatkan pelayanan dari suatu sistem. Dibutuhkan perkembangan pada setiap sistem yang ada agar pelayanan tersebut dapat berjalan dengan maksimal. Dapat dikatakan sebuah pelayanan memiliki aturan masing-masing sebagai contoh adalah waktu pelayanannya. Sebuah pelayanan diharuskan memiliki ketentuan waktu pelayanan agar Customer dapat terlayani dengan baik.

Namun terkadang Staff yang melayani merasa masalah yang akan dipecahkannya terlalu berat sehingga membutuhkan waktu lebih untuk mengatasinya. Hal ini akan berdampak buruk terhadap pelayanan. Pelayanan akan terganggu karena tidak sesuai dengan waktu yang telah ditentukan. Perguruan Tinggi Raharja sebagai salah satu lembaga pendidikan unggulan yang berada di Kota Tangerang, selalu berusaha menjawab segala permasalahan yang ada saat ini. 
Dengan memanfaatkan internet, Perguruan Tinggi Raharja mencoba untuk membuat sebuah terobosan baru yang bisa menyelesaikan masalah pelayanan tersebut yaitu dengan pengembangan pada sistem ROOSTER. Sistem pelayanan yang sudah berjalan ini adalah salah satu dari 10 pilar iLearning yang ada pada Perguruan Tinggi Raharja. Seperti pada gambar berikut :

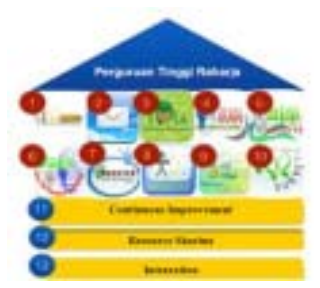

\section{Gambar 1 .10 Pilar IT iLearning}

Dengan adanya pengembangan pada sistem ROOSTER ini diharapkan dapat memberikan kenyamanan kepada para pengguna dan juga dapat memberikan pelayanan yang maksimal dengan meminimalisir kemungkinan yang menghambat suatu pelayanan tersebut guna memuaskan para customer dengan hasil pemecahan masalah yang telah diberikan.

\section{PERMASALAHAN}

Pada dasarnya Perguruan Tinggi telah mempunyai banyak cara yang dapat digunakan untuk dapat mengoptimalkan sistem yang ada (ROOSTER) salah satunya yaitu dengan membuat perkembangan dalam sistemnya sehingga pelayanan yang ada dapat berjalan dengan optimal. Namun tidak banyak pelayanan yang dapat berjalan dengan optimal.

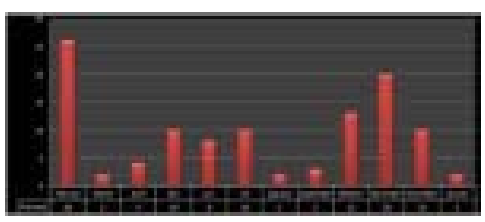

Gambar 2 .Overdue ticket 
Seperti yang terlihat pada grafik diatas bahwa cukup banyaknya tiket yang tidak dapat diselesaikan dengan baik yang berakibat overdue-nya tiket tersebut. Hal ini menjadi masalah utama yang ada dalam sistem pelayanan kampus karena ROOSTER berperan penting guna menindaklanjuti permasalahan yang tidak dapat diselesaikan oleh para operator iDuHelp! yang telah bertugas. Jika overdue tiket ini bertambah terus maka hal ini pun akan berdampak buruk pada kualitas dari sistem tersebut.

Maka dapat disimpulkan dalam hal ini terdapat 3 (tiga) permasalahan yang ada. Pada permasalahan pertama adalah kurangnya waktu pelayanan. Karena tidak adanya alternatif untuk menambahkan waktu pelayanan sehingga banyak pelayanan yang terabaikan. permasalahan yang kedua yaitu pelayanan menjadi terhambat.

Banyak pelayanan yang terhambat karena masalah yang dipecahkan membutuhkan banyak waktu dalam memprosesnya sehingga pelayananannya menjadi sangat buruk. Permasalahan ketiga adalah Banyaknya overdue tiket di ROOSTER. Karena kurangnya waktu yang dibutuhkan dalam memecahkan masalah yang ada maka banyak tiket yang overdue. Dengan adanya overdue tiket ini maka hal ini dapat mempengaruhi penilaian dari sistem yang ada.

Untuk mengetahui dengan jelas intisari dari permasalah yang ada maka digambarkan ke dalam bentuk Mind Mapping seperti gambar di bawah ini :

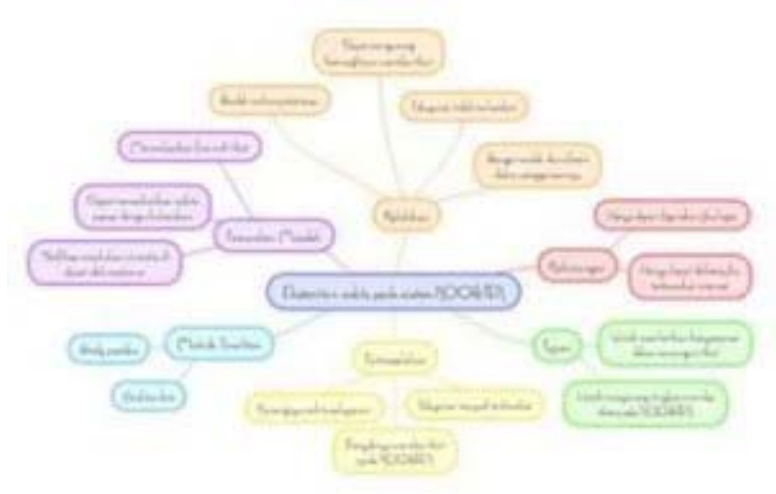

Gambar 3. Mind Mapping Ekstention waktu pada ROOSTER 
Dari permasalahan tersebut, maka diperlukan suatu sistem yang dapat memberikan kenyamanan kepada para Staff yang bertugas agar masalah yang dipecahkan dapat dilakukan dengan maksimal sesuai dengan waktu yang dibutuhkan.

Oleh karena itu, Perguruan Tinggi Raharja sebagai salah satu lembaga pendidikan unggulan berusaha untuk menyelesaikannya. Dengan memanfaatkan ilmu teknologi, Perguruan Tinggi Raharja mencoba membuat suatu pengembangan sistem dengan menggunakan fitur edit tiket pada sistem yang ada.

\section{LITERATUR REVIEW}

Metode study pustaka dilakukan untuk menunjang metode wawancara dan observasi yang telah dilakukan. Pengumpulan informasi yang dibutuhkan dalam mencari referensi-referensi yang berhubungan dengan penelitian yang dilakukan.

Banyak penelitian yang sebelumnya dilakukan mengenai tiket online dan penelitian lain yang berkaitan. Dalam upaya mengembangkan dan menyempurnakan sistem tiket online ini perlu dilakukan studi pustaka (literature review) sebagai salah satu dari penerapan metode penelitian yang akan dilakukan. Diantaranya yaitu:

1. Penelitian yang dilakukan oleh Cagla Ozen Seneler, Nuri Basoglu, dan Tugrul U. Daim, dari University of York, York Inggris, pada tahun 2010 yang berjudul "An empirical analysis of the antecedents of adoption of online services: A prototype-based framework”. Penelitian ini dimaksudkan untuk memperluas teori adopsi teknologi dengan mengintegrasikan mereka dengan orang-orang menjelajahi inovasi layanan dan upaya untuk mengeksplorasi faktor-faktor yang membantu atau menghalangi sikap terhadap menggunakan layanan online. Dengan demikian, penelitian ini bertujuan untuk memberikan wawasan tentang atribut yang pengembang dan desainer dari layanan tersebut harus memperhatikan. Studi ini menyelesaikan tujuan di atas melalui pengujian kerangka kerja yang dikembangkan sebagai hasil dari literatur review, wawancara dan kelompok ahli yang terfokus serta survei. Satu set prototipe dikembangkan sebagai antarmuka alternatif untuk layanan online. Ada peningkatan minat dalam desain dan pengembangan layanan yang lebih baik. Dalam hal ini layanan online, mengembangkan antarmuka pengguna yang lebih baik dengan teknologi yang berbeda sangat penting, karena kemampuan 
antarmuka pengguna menambahkan banyak untuk menggunakanTeknologi Informasi ( TI ) proses adopsi. Jadi menempatkan penekanan pada pemasaran dan pengguna pelatihan yang lebih baik akan membantu adopsi layanan online.[1]

2. Penelitian yang dilakukan oleh Ferry Sudarto, Hidayati dan Ageng Setiani Rafika pada tahun 2011 yang berjudul "Peningkatan Mutu Ujian Dari Paper Based Menuju Computer Based ”. Penelitian ini membahas perihal Aplikasi komputer sebagai bagian integral dalam sistem ujian terhadap proses pembelajaran dan mengajar yang bertujuan mempermudah siswa dalam proses ujian. Ujian berbasis komputer juga merupakan salah satu usulan yang dapat mengurangi tingkat kecurangan dalam proses ujian. Ujian yang berjalan melalui pola interaksi dua arah melalui terminal komputer maupun multi arah yang diperluas melalui jaringan komputer (baik lokal maupun global) dan juga diperluas fungsinya melalui interface (antar muka) multi media.[2]

3. Penelitian yang dilakukan oleh Untung Rahardja, Nur Azizah dan Santika Dewi dari Perguruan Tinggi Raharja, Indonesia, pada tahun 2013 yang berjudul“Sistem Pelayanan Dukungan Role Online System Ticketing Raharja(ROOSTER) Dengan Menggunakan E-Ticket”. Penelitian ini menjelaskan sebuah website sebagai media interaksi dengan menggunakan e-Ticket yang bertujuan untuk memudahkan proses pelayanan dukungan, selain itu juga memberikan kemudahan kepada pemakai untuk dilayani. Proses pelayanan dukungan dapat dilakukan dengan cara online sehingga menambah kemudahan dalam proses pelayanan dukungan. Pada Perguruan Tinggi Raharja, sistem pelayanan dukunganROOSTER (Role Online System Ticketing Raharja) yang diterapkan ditujukan untuk memberikan pelayanan yang efektif dan efesien kepada seluruh civitas akademika Perguruan Tinggi Raharja. Dalam penelitian ini korelasi yang berhubungan dengan penelitian yang dilakukan adalah penggunaan ticketing online yang dapat memudahkan sitem pelayanan menjadi terarah dan tersusun secara sistematis dengan adanya penomoran tiket yang terurut.[3]

4. Penelitian yang dilakukan oleh Eva Rosyifa dari Perguruan Tinggi Raharja, Indonesia, pada tahun 2012 yang berjudul "Penerapan Campus Service System iDuHelp! Dalam Mendukung Kegiatan iLearning Education (iDu) Pada Perguruan Tinggi Raharja”. Penelitian ini digunakan pada sebuah sistem pelayanan chat online dan offline pada perguruan tinggi Raharja, yang nantinya 
akan digunakan untuk para Pribadi Raharja yang ingin mengetahui informasi seputar akademik, dan calon mahasiswa baru yang ingin mengetahui informasi kampus. Metode penelitian yang digunakan pada penulisan skripsi ini adalah metode observasi dan studi kepustakaan. Kelebihan sistem yang terdapat pada penelitian ini adalah user friendly dan mudah digunakan, kekurangan masih tidak jelasnya sasaran yang di tuju, dan penghitungan mahasiswa yang menggunakan sistem iDuHelp! masih manual.

Hasil studi pustaka (literature review) ini mendemonstrasikan landasan (platform) yang kokoh (level 2) serta alasan yang kuat untuk mengembangkan Sistem informasi media publikasi penyampaian informasi menjadi lebih baik lagi dengan pertimbangan yang sudah matang. Kesenjangan (gaps) telah teridentifikasi dengan baik sehingga tidak terjadi pembuatan ulang (reinventing the wheel).

Peninjauan telah dilakukan dengan matang, sehingga dipastikan akan menghasilkan project yang maksimal, menjadi lebih efektif, memudahkan akademik memberikan informasi kepada mahasiswa (stakeholder) merasa puas serta terlayani dengan baik (service excellence).

Oleh karena itu, untuk menindaklanjuti penelitian sebelumnya seperti yang dikemukakan diatas, maka dilakukan penelitian untuk penggunaan ekstention waktu dalam role online system ticketing raharja (rooster) sebagai penunjang pelayanan iduhelp!.

\section{PEMECAHAN MASALAH}

ROOSTER (Role Online Sytem Ticketing Raharja ) merupakan sistem pelayanan informasi dengan menggunakan sebuah tiket yang akan diberikan kepada pihak yang terkait (staff ROOSTER), agar dapat memberikan informasi yang akurat. ROOSTER ini digunakan pada perguruan Tinggi Raharja yang bertujuan untuk menunjang sistem pelayanan yang ada pada Perguruan Tinggi Raharja, salah satu contohnya adalah pelayanan iDuHelp! yang sedang berjalan saat ini.[5]

Kinerja ROOSTER dalam menunjang sistem pelayanan iDuHelp! pada Perguruan Tinggi Raharja juga diharapkan dapat memberikan informasi yang terpercaya, sehingga mahasiswa tidak lagi meragukan informasi yang didapatkan 
dari sistem pelayanan iDuHelp! dan diharapkan mahasiswa tidak lagi mengalami kesulitan dalam memperoleh informasi mengenai :

1. 10 Pilar It iLearning ( iMe, Rooster, iDuHelp!, iDu, Widuri, iRme, Magics, iRan, iSur, Rinfo )

2. REC (Hibah, Jurnal, Traning, RCEP, SIS+ dan RME )

3. iFacility : Wifi ilearning REC, dan Komputer REC

4. iPanda, FOX, Youtube Channel, iTracking, GO+, iTunesU.

Dengan melihat permasalahan yang terjadi maka perlu adanya fitur Ekstention waktu untuk para staff yang bertugas agar pelayanan dapat berjalan dengan baik. Fitur edit tiket ini berguna untuk memenuhi waktu pelayanan yang dibutuhkan para staff yang membutuhkan waktu lebih lama dari prosedur yang ada karena tingkat kesulitan dari masalahnya. Fitur ini pun dapat mengurangi tingkat overdue tiket dan tentunya ini akan membuat pelayanan menjadi lebih baik dan pelayanan pun tidak terhambat karena adanya email notifikasi dari sistem sebagai peringatan jika terdapat perubahan pada tiket yang telah dibuat oleh customer sehingga customer pun tidak merasa masalahnya diabaikan.

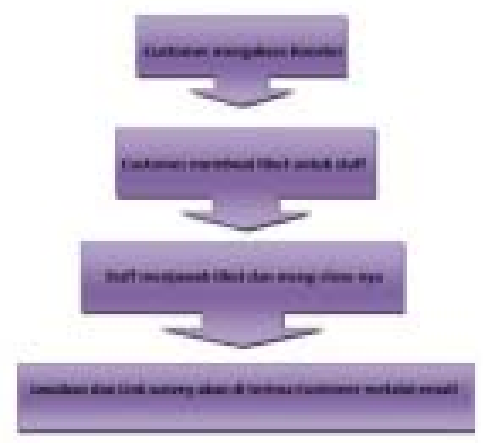

Gambar 4. Alur pelayanan Rooster

Gambar di atas adalah alur dari pelayanan ROOSTER yang telah berjalan. Dapat dilihat bahwa alur sistem ROOSTER berjalan dimulai dengan Customer yang 
mengakses ROOSTER untuk meminta staff memecahkan masalah yang ada dengan membuta tiket yang langsung ditujukan kepada staff yang bertugas. Setelah itu staff yang bertugas tersebut harus menyelesaikan permasalahan tersebut dengan memberikan solusi tanpa mengabaikan tiket tersebut.

Jika permasalahan telah teratasi maka staff memberikan survey kepada customer untuk di isi oleh customer dan menutup tiket yang telah diselesaikan. Dengan adanya pengembangan maka dapat dipastikan pelayanan yang berjalan dapat berjalan lebih maksimal.

Di bawah ini merupakan gambaran flowchart staff dari alur program yang berjalan dari sistem ROOSTER.

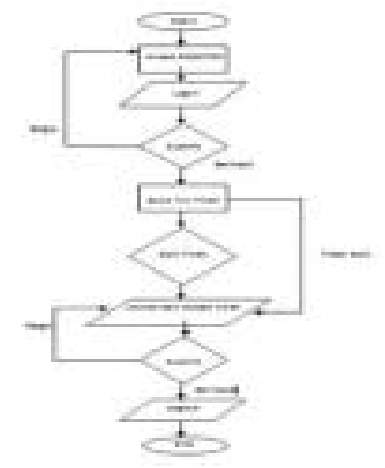

\section{Gambar 5. Flowchart staff}

Gambar di atas menjelaskan proses yang dilakukan oleh staff dalam penyelesaian permasalahan yang ada. Dalam hal ini, kontrol sistem informasi dengan menggunakan ROOSTER merupakan konsep dari sebuah peningkatan dari pelayanan sistem kampus yang yang telah diimplementasikan. Selain itu pengembangan pada ROOSTER dapat mendukung sistem iLearning yang ada pada Perguruan Tinggi Raharja yang sudah berbasis teknologi.

\section{Listing Program}

ROOSTER adalah salah satu pelayanan kampus dalam bentuk pembuatan tiket online yang berguna untuk menyelesaikan permasalahan yang belum terpecahkan 
oleh operator iDuHelp!. Dalam pengembangannya sistem ROOSTER menitik beratkan pada ekstention waktu pelayanannya, sehingga listing program yang akan ditampilkan yaitu listing program edit tiket pada sistem ROOSTER. Berikut listing programnya :

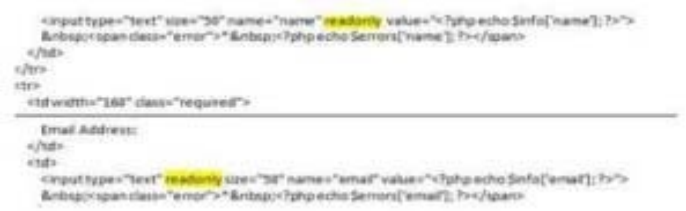

Gambar 6. Listing Program edit ticket

Untuk Metode yang digunakan dalam pemecahan masalah ini adalah dengan menggunakan study pustaka (Literature review), analisa data dengan cara memahami masalah yang ada dan mencari pembaruan tentang sistem pelayanan agar pelayanan lebihmaksimal.

\section{IMPLEMENTASI}

Dibawah ini adalah tampilan dari fitur edit tiket yang dapat dilakukan oleh staff untuk menambahkan waktu pelayanannya :

\section{a. Tampilan Login ROOSTER}

Pada tampilan ini kita bisa melihat tampilan Login pada sistem ROOSTER.

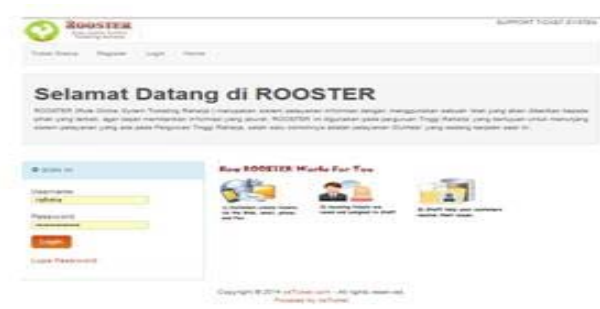

Gambar 7. Tampilan Login ROOSTER 
b. Tampilan Open Ticket

Pada tampilan ini terdapat isi dari tiket yang Open (belum ditangani).

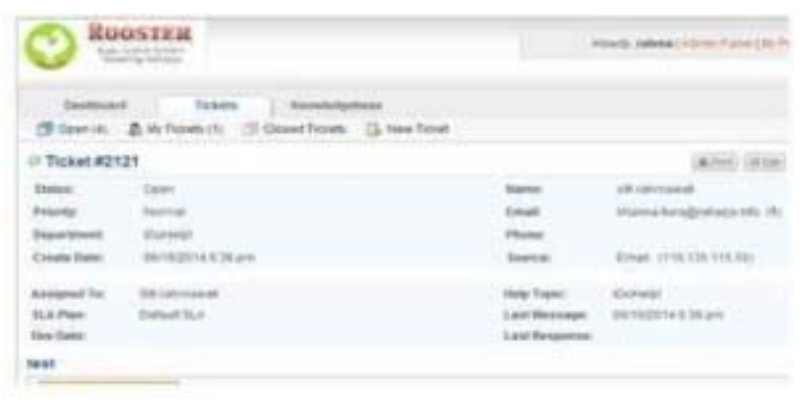

Gambar 8. Tampilan Open ticket

c. Tampilan Edit tiket

Pada Tampilan ini Staff dapat mengedit tiket dengan menambahkan waktu penanganan sesuai dengan kebutuhannya dan juga memberikan alasannya pada bagian internal note.

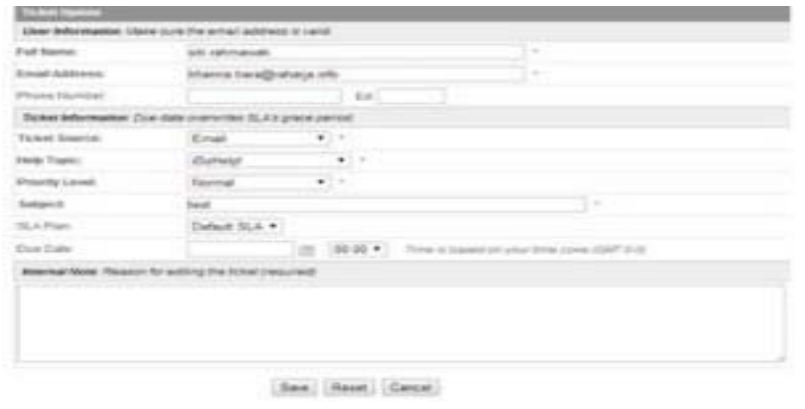

Gambar 9. Tampilan Edit tiket

d. Tampilan tiket yang telah diedit

Tampilan ini adalah tampilan tiket yang telah berhasil diedit oleh staff yang bertugas. 


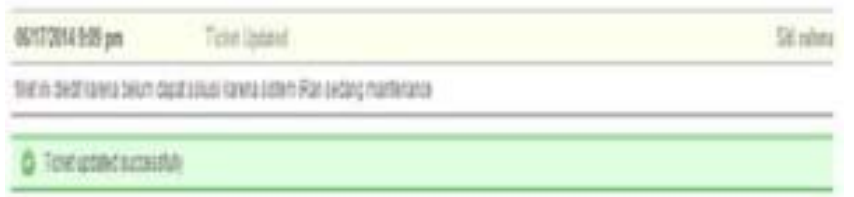

Gambar 10. Tampilan tiket yang telah diedit

\section{KELEBIHAN}

Dengan sebuah sistem ini staff dapat menyelesaikan permasalahannya dengan baik tanpa mengabaikan tiket sehingga tiket menjadi overdue. Beberapa kelebihan dari pengembangan sistem ini adalah sebagai berikut :

1. Pelayanan tidak terhambat.

2. Sistem sudah terkomputerisasi.

3. Sangat mudah dan efisien dalam penggunaanya.

4. Dapat mengurangi kemungkinan dari overdue tiket.

5. Mempermudah staff dalam menangani tiketnya.

6. Terdapat email notifikasi

\section{KEKURANGAN}

Dari sistem yang dibuat ini, tidak luput dari sebuah kekurangan. Kekurangan dari sistem ini adalah :

1. Hanya dapat digunakan jika sudah login di ROOSTER.

2. Harus tergantung/menggunakan jaringan internet. 


\section{KESIMPULAN}

Guna mengurangi tingkat overdue tiket maka para staff dapat menggunakan fasilitas edit tiket dengan cara menambahkan waktu yang dibutuhkan dengan syarat memberikan alasan pada internal note yang berisikan penambahan waktu penanganan.Hal ini sangat berguna untuk staff yang bertugas.

Jika staff membutuhkan waktu penanganan yang lebih lama maka staff dapat memberikan ekstention waktu pada tiket tersebut sehingga waktu pelayanan sesuai dengan waktu yang dibutuhkan. Dengan adanya ekstention waktu pelayanan yang ada pun tidak akan terhambat karena adanya email notifikasi yang akan terkirim kepada email customer jika tiket tersebut diedit waktunya yang menandakan staff membutuhkan waktu lebih selama memproses kebutuhan customer tersebut.

\section{DAFTAR PUSTAKA}

[1] Dewi, Santika. 2013. Perancangan Role Online System Ticketing Raharja (ROOSTER) Dalam Mendukung Sistem Pelayanan Pada Perguruan Tinggi Raharja. Skripsi, Perguruan Tinggi Raharja. Tangerang.

[2] Ferry Sudarto, Hidayati danAgeng Setiani Rafika (2011), "Peningkatan Mutu Ujian Dari Paper Based Menuju Computer Based ”. CCIT Journal Vol.5 No.3. Tangerang : Perguruan Tinggi Raharja

[3] iMe ROOSTER. 2013. About ROOSTER. (Tanggal akses 28 April 2014)

[4] Rosyifa, Eva. 2012. Penerapan Campus Service System iDUHELP! Dalam Mendukung Kegiatan iLearning Education (iDu) Pada Perguruan Tinggi Raharja. Skripsi, Perguruan Tinggi Raharja. Tangerang.

[5] Seneler. Ozen. Cagla, Basoglu. Nuri, Daim. Tugrul U. 2010. An empirical analysis of the antecedents of adoption of online services: A prototype-based framework. Journal of Enterprise Information Management, Vol. 23 Iss: 4. University of York,Inggris. 